\title{
Cultura visual e homossexualidades na constituição de "novas" infâncias e "novos" docentes*
}

ANDERSON FERRARI Colégio de Aplicação João XXIII - UFJF Universidade Federal de Juiz de Fora

\section{INTRODUÇÃO}

Neste artigo venho reafirmar meu interesse nas articulações entre as sexualidades e a cultura, tomando a educação como campo de análise desse encontro. Para isso, vou tomar como detonadora da discussão a versão reduzida de um documentário catalão sobre famílias homoparentais destinado às escolas. Temática recente e pouco explorada na produção acadêmica, a relação entre escolas e famílias homoparentais, estabelecida a partir das imagens, convida-nos a pensar os atravessamentos entre formação docente, educação infantil e relações de gênero/sexualidades. Não somente no que se refere à educação escolarizada, mas explorando o termo "educação" no seu sentido mais amplo, vinculado aos processos de constituição dos sujeitos. No primeiro caso quero me debruçar nos artefatos, práticas, discursos e imagens que chegam às escolas, que são acionadas por professores e alunos, que invadem e são trazidas para sala de aula, enfim situações que acontecem no interior das escolas ou que são voltadas para esse espaço. No outro caso, o meu investimento está em

* Texto apresentado em Sessão Especial na 34a Reunião Anual da ANPEd, realizada de 02 a 05 de outubro de 2011, em Natal-RN. 
problematizar essas e outras relações para além delas. Isso significa afirmar que tomo os exemplos que recorrentemente trago para os artigos como detonadores de uma discussão e de um exercício que me parecem interessantes para o campo da educação: colocar sob suspeita as maneiras como vamos estabelecendo e constituindo posições de sujeitos no interior de uma cultura.

Homo Baby Boom é o título do documentário. No entanto, Homo Baby Boom é mais do que um documentário. Trata-se da produção e distribuição de um material elaborado por uma associação de famílias homoparentais, ou seja, algo que traduz um tipo de intervenção na cultura, na escola e nos sujeitos que não ocorre somente na realidade espanhola, mas que também se constitui como ação de grupos similares no Brasil. Desde a década de 1990, os diferentes grupos Lésbicas, Gays, Bissexuais, Travestis e Transexuais (LGBTT), vêm investindo na produção de material destinado às escolas, aos professores e aos alunos, além da proposição e organização de cursos de capacitação formais de professores e professoras. No entanto, o que me chama atenção é outro tipo de investimento nos professores, mais sutil, fluido e difuso, que ocorre por meio de filmes, documentários e todo tipo de material em que as imagens estão presentes, e que a produção catalã nos instiga a pensar. É essa ação sobre os professores, escolas e alunos que passa pela socialização de um tipo de saber elaborado no interior dos grupos, que se refere a uma intencionalidade e se utiliza das experiências, dos corpos e sujeitos que estou chamando de formação docente e me interessa problematizar neste artigo.

Essas preocupações me conduzem a diferentes áreas do conhecimento e me possibilitam estabelecer ligações entre elas, sobretudo com base em meu foco de interesse, que são as homossexualidades masculinas. Vinculadas às questões que envolvem a construção de conhecimento e das subjetividades de alunas e alunos, professoras e professores, principalmente em torno dos discursos produzidos das sexualidades e das diferenças ao longo da História, essa problemática central das identidades homossexuais me possibilita navegar pela formação docente, pelos currículos, pelo gênero e sexualidades, pela educação infantil, pelos movimentos sociais, pela educação fundamental, entre outras.

Atravessadas por relações de poder (Foucault, 1987, 1988), o trabalho com a produção das diferenças representa uma escolha política de dar voz à diversidade que compõe a escola. Desta forma, no diálogo entre a formação de professores, educação infantil, relações de gênero e sexualidades, quero problematizar esse documentário sobre famílias homoparentais voltado para escolas, sobretudo para a educação infantil, para pensar essa produção audiovisual no que se refere à cultura visual e sua vinculação com a formação de um "novo" docente e "novas" identidades sociais e sexuais. Como afirma Uziel (2007, p. 73-4), "as famílias homoparentais interpelam os cientistas sociais a respeito de estruturas de parentesco; os juristas sobre a filiação; os psicólogos no que concerne ao desenvolvimento de crianças em famílias diferentes das tradicionais". Portanto, a preocupação com essas questões e como elas estão intimamente relacionadas aos limites da escola, ao desafio de transgredir e repensar as práticas e posturas dos professores, a formação docente e a construção das subjetividades dos sujeitos envolvidos nesses processos são centrais nesta escrita. 


\section{HOMO BABY BOOM}

Homo Baby Boom: Famílies de lesbianes i gais é uma produção de Anna Boluda, da Associació de Famílies Lesbianes i Gais, situada na Catalunya, Espanha. Uma associação que existe desde 2001, que congrega famílias homoparentais na luta por seus direitos. Em 2009, essa instituição produziu um kit composto de dois DVDs, voltado para as escolas e que tem como função principal mostrar a vida cotidiana das famílias homoparentais. "Homoparentalidade" foi um termo cunhado na França em 1997 pela Association des Parents et Futurs Parents Gays et Lesbiens (APGL), por ocasião da discussão da união civil (Uziel, 2007), para nomear os novos arranjos familiares compostos por pessoas do mesmo sexo biológico.

No primeiro DVD está o documentário Homo Baby Boom, em duas versões: uma de 27 minutos destinada a professoras, professores e toda comunidade escolar, e outra mais reduzida, de nove minutos, direcionada a crianças e adolescentes. Há outro DVD intitulado "Guia didático" contendo imagens do cotidiano dessas famílias, que também estão presentes no documentário.

É essa versão reduzida do documentário tendo a criança como foco que quero tomar como motivador da discussão em torno da formação docente, educação infantil e sexualidades. O que leva uma instituição de famílias homoparentais a produzir um documentário sobre seu cotidiano direcionado à escola, a professoras e professores e a crianças e adolescentes? Que discursos estão organizando esse documentário e que imagens estão construindo? Que espaços de discussão ele nos permite? Com essas questões quero pensar na relação da cultura visual com a formação docente e com o investimento em um "novo". "Novas identidades sexuais e sociais" - famílias homoparentais que dão origem a filhas e filhos de casais de lésbicas e gays -, identidades sociais vinculadas diretamente às sexualidades. "Nova escola" - aquela que recebe essas "novas" crianças dessa "nova" constituição familiar -, uma situação que implica desafios e possibilidades, limites e potencialidades. "Novas professoras e professores" - aquelas e aqueles que vão lidar diretamente com essas crianças e suas famílias no contexto da sala de aula junto a outras crianças -, o que "induz" a investimento em informação e conhecimento, enfim, em formação.

A versão reduzida pode ser dividida em oito blocos de discussão. No primeiro, é possível identificar a preocupação em esclarecer e definir o que é uma família homoparental. O documentário inicia com a câmera acelerada em que diferentes famílias vão chegando para compor uma grande foto e uma voz ao fundo anuncia: "Todas estas personas tienen una cosa en comum. Son miembros de una família homoparental. Es decir..”. Há um corte e aparece em seguida a imagem focada num menino - Josep, de 4 anos - que fornece um conceito, completando a frase interrompida: "Una família de lesbianas y gays que tiene una madre y outra madre, o un padre y outro padre". Voltando a imagem para as famílias, a voz ao fundo fornece outras informações que complementam a preocupação em definir, deixar claro e, ao mesmo tempo, construir um conhecimento e informar aqueles que desconhecem essas possibilidades de constituição de famílias: "o una madre lesbiana sola, o un padre gay solo, o bien son 
familias reconstituidas con hijos de relaciones heterosexuales anteriores. No es un fenómeno nuevo, y no hay cifras exactas, pero en los últimos años han aumentado mucho. La mayoría están formadas por mujeres que han optado por la reproducción asistida [...]. En otros casos los hijos e hijas proceden de la adopción internacional. Y desde el año 2005, también es posible la adopción nacional conjunta”.

Há um corte nas imagens das famílias e aparece uma segunda criança como protagonista na condução do roteiro. É Jordi, de 6 anos, que apresenta sua família. Novamente é utilizado o recurso de focar na criança, fortalecendo seu papel como condutor da apresentação, além de contar com um movimento da câmera de seguir a criança. Nessa segunda parte, a preocupação parece estar centrada no dia a dia dessas famílias. E assim Jordi apresenta sua família: "Ésta es Maria, mi madre. Ésta es Miriam, mi hermana. Ésta es Marissol, mi madre. Ésta es Rita, mi hermana. Y yo soy Jordi”. Feita a apresentação dessa família de três crianças e duas mães, todos na sala passamos a conhecer, pelas imagens, o cotidiano dessas pessoas. Isso sucede com outras duas famílias, sempre com as crianças apresentando dois pais, ou duas mães, irmãs e irmãos, passando para um segundo momento do cotidiano das casas em que essas crianças aparecem andando de bicicleta, cozinhando, estudando, desenhando, enfim, nas situações mais cotidianas e comuns de qualquer outra família.

$\mathrm{Na}$ terceira parte, a ênfase está em como as crianças nomeiam e buscam solucionar possíveis confusões, ou seja, em como elas lidam com essas composições. Permanecendo a imagem no cotidiano das famílias, temos o retorno da comentarista: "Como Jordi y sus hermanas tienen dos madres, han buscado la manera de llamarlas sin confundirlas". Ato contínuo, a imagem foca em uma das mães, que explica: "A mi me hacía mucha ilusión que me dijeran mamá, y como se puede decir mamá y madre, lo hicimos asî". Volta a imagem para a criança, que completa: "La mamá es Marissol, y la madre es Maria”. Seguindo a mesma lógica de mostrar outras famílias e suas maneiras de organizar-se, é a vez de Vasyl, outra criança que nos apresenta: "Los llamo así: papá Carles, papá Jordi o papás”.

Até aqui as crianças são centrais na preocupação, condução do documentário e nas imagens. Da quarta parte em diante, elas somem e o destaque está em outras questões, sem que as crianças sejam o foco principal.

Assim, na quarta parte encontramos como os pais ou as mães lidam nessas constituições familiares. Como se dividem nos afazeres da casa e no cuidado com os filhos e filhas? Qual deles é o responsável em fazer a comida, dar banho, levar e pegar na escola, frequentar reuniões de pais? Vão se revezando no vídeo as três famílias no exercício de suas responsabilidades de forma que fala e imagem se reforçam. $\mathrm{Na}$ parte seguinte a discussão toma outro rumo, atual e importante para os grupos gays e implicada na existência dessas famílias, que é o direito e as conquistas legais. Tendo as crianças como coadjuvantes, passamos a ver imagens caseiras de casamentos entre pessoas do mesmo sexo que compõem o documentário, e a comentarista ao fundo: "Estas famílias nunca habían tenido los mismos derechos que las que tienen un padre y una madre. Pero, desde 2005, ya es posible tener legalmente dos madres o dos padres. Y, además, se pueden casar”. 
Os blocos seis, sete e oito são centrados nos adolescentes e no modo como lidam com seus amigos na escola, com as questões relacionadas à identidade sexual e como convivem com outros iguais a eles. Dessa forma, o bloco seis é dedicado aos encontros que essa associação programa entre famílias homoparentais e a importância disso: "De vez en cuando estas familias se reúnen con otras que tienen madres lesbianas o padres gays. Allí pueden conocer a más niños y niñas de su edad, más pequeños, o mayores, incluso adolescentes". Uma fala acompanhada pelas imagens desses encontros em que vemos adolescentes e crianças em brincadeiras esportivas, oficinas e outras atividades. Entramos então em outra composição de imagens, desta vez com adolescentes dando depoimentos sobre como lidaram com essa nova identidade de filhas e filhos de famílias homoparentais. Conhecemos, assim, histórias de superação e organização diante de outros contextos sociais. O último bloco é reservado para esclarecimentos sobre a identidade gay, mais especificamente um certo cuidado em explicar e esclarecer que ser filho ou filha de homossexuais não significa ser também homossexual. É a comentarista que inicia o tema: "Algunas personas creen que los hijos y hijas de gays y lesbianas también serán homosexuales, pero ellos no están de acuerdo". E seguem os depoimentos: "Eso es una chorrada, como una catedral. Yo, por ejemplo, no soy lesbiana, igual que, hay muchas lesbianas que vienen de familias heterosexuales". E a produção termina com uma última fala da comentarista e imagens das famílias: "Desde hace más de 30 años, diversos estudios en todo el mundo han buscado diferencias entre los hijos y hijas de estas familias y los que tienen un padre y una madre y la única que han encontrado es que son más tolerantes".

\section{CRIANÇAS “INVENTADAS”: FILHOS E FILHAS DE FAMÍLIA HOMOPARENTAL}

Definir um título como "crianças inventadas" significa pensar no poder das palavras, dos discursos e das imagens na constituição de identidades. Esse é um aspecto que me parece forte no documentário. Tratando-se de um documentário produzido por uma associação de famílias de lésbicas e gays, podemos nos perguntar: até que ponto ele está servindo para sustentar a existências dessas famílias? O sentido de família está implicado em ter filhos. Em nenhum momento aparecem famílias de pais ou mães sem filhos. Nesse sentido, há um discurso produzido pelo documentário, seja ele materializado pelas falas, depoimentos, definições, ou mesmo pelas imagens que vão dialogando com o que é dito, que vai construindo a mensagem da produção, sua intenção.

Ellsworth (2001), ao discutir os modos de endereçamento no cinema, ajuda-nos a problematizar os filmes produzidos para escolas, assim como aqueles que são utilizados com algum fim pedagógico. Uma perspectiva de análise que me inspira pensar as imagens e a relação entre cultura visual e subjetividades. Vinda do Cinema e iniciando sua vida acadêmica como professora, a autora surpreende-se pela ausência da teoria do modo de endereçamento na formação de professores. $\mathrm{O}$ modo de endereçamento é uma teoria originaria do Cinema, que envolve teoria, 
política e mudança social. Os textos, os filmes e as propagandas são feitos para alguém, ou seja, para um público-alvo. Segundo a autora, todo filme trabalha com duas questões: quem o filme pensa que eu sou? Quem o filme quer que eu seja? Duas questões que são investimentos em algum tipo de mudança social, na medida em que trabalham com a perspectiva de transformação dos sujeitos que estão assistindo ao filme, que são capturados por algum endereçamento da produção. Questões que, trazidas para o campo da educação, podem se transformar em "quem eu penso que os meus alunos são?" e "quem eu quero que eles sejam?”. Num campo ou outro do conhecimento trabalham com as imagens que eu tenho do meu público-alvo e de onde eu quero levá-los, apostando na mudança social.

Nesse sentido, que discursos são produzidos por um documentário sobre famílias homoparentais destinado às escolas e, mais especificamente, às crianças e aos adolescentes? Que discursos são reforçados, desconstruídos, instituídos pelas linguagens audiovisuais? Podemos indicar alguns, tais como: a constituição de um tipo de homossexual e lésbica dentro de um parâmetro heteronormativo de casamento, a construção da ideia de família vinculada à presença de crianças e filhos, a necessidade de demonstrar que essas uniões não são novas nem tampouco pequenas e que se constituem como um movimento sólido, natural e "normal". Além dessas possibilidades de análise, as que me interessam são aquelas que dizem da produção discursiva desses artefatos audiovisuais no que se refere às infâncias e à formação docente.

Butler (2009), ao analisar a articulação entre linguagem, poder e identidade, destaca que as identidades são produções que os sujeitos colocam em ação por meio de suas indicações linguísticas e expressões. Com base na elaboração do conceito de performatividade, a autora busca pensar os conflitos performativos que são acionados e que regulam a produção normativa das identidades de gênero e sexuais. Esses dois pontos em articulação tomam como performativas as palavras que "fazem o que dizem" ao serem pronunciadas. Assim, performatividade envolve toda circulação de discurso com capacidade para controlar a emergência e construção das subjetividades.

Performatividade une a materialidade das palavras e dos discursos com a perspectiva disciplinar e o corpo dócil de Foucault. Num investimento pelo corpo e sujeito produzidos e contidos pela disciplina, a escola investe no controle das sexualidades, contribuindo na construção de subjetividades normativas e abjetas. Assim sendo, as homossexualidades não estão presentes nas escolas como um tema a ser discutido, desconstruído, relacionado com o conteúdo, permanecendo com um sentido de "anormalidade", antinatural, o que reforça o lugar das heterossexualidades como algo normal e natural. Dessa forma, podemos partir do pressuposto de que produzir um documentário sobre famílias homoparentais direcionado às escolas é uma forma de inserir a discussão. Mas, mais do que isso, é uma maneira de existir. E essa necessidade de existir conduz a uma inserção no modelo de união que está posto, que também é incorporado por lésbicas e homossexuais. É um processo de individualização e socialização que é próprio dos processos de construção de identidades. Em meio a tudo isso, vão inventando uma infância, constituída de crianças e adolescentes, filhos e filhas de famílias homoparentais, filhos e filhas de lésbicas e gays. 
Identidade que está diretamente relacionada à diferença (Woodward, 2000). Não existe identidade sem diferença, de forma que afirmar "sou gay ou lésbica", implica ao mesmo tempo estabelecer uma identidade pela diferença, uma vez que a afirmação "sou gay" só é entendida porque traz junto a negação "não sou heterossexual". A diferença é uma forma de individualizar. Eu sou gay, diferente dos heterossexuais, mas igual a tantos outros, que constituem o coletivo dos homossexuais e lésbicas. Assim, a identidade homossexual, como todas as outras, vai sendo construída em meio ao processo de individualizar e coletivizar. Esse mesmo mecanismo é utilizado pelos discursos que aparecem no documentário no que se refere ao entendimento de uma infância específica, ou seja, crianças filhas e filhos de famílias homoparentais, filhas e filhos de lésbicas e gays.

A infância é algo capturado por inúmeras instituições, tornando-se objeto de conhecimento e algo sobre o qual se pode falar.

A infância é algo que nossos saberes, nossas práticas e nossas instituições já capturaram: algo que podemos explicar e nomear, algo sobre o qual podemos intervir, algo que podemos acolher. A infância, desse ponto de vista, não é outra coisa senão o objeto de estudo de um conjunto de ações mais ou menos tecnicamente controladas e eficazes, ou a usuária de um conjunto de instituições mais ou menos adaptadas às suas necessidades, às suas características ou às suas demandas. Nós sabemos o que são as crianças, ou tentamos saber, e procuramos falar uma língua que as crianças possam entender quanto tratamos com elas, nos lugares que organizamos para abrigá-las. (Larrosa, 2004, p. 96)

Escolas, cinema, cursos de licenciatura, livros, seminários, enfim, uma legião de pessoas vai se sentindo especialista para falar sobre a infância e, por consequência, sobre crianças. Os grupos LGBTTs também entraram nessa disputa, interessados em desconstruir imagens negativas das homossexualidades, assim como possibilitar outras mais positivas, num investimento que passa pela escola. E, em se tratando de homossexualidades, os membros desses grupos adquirem uma autoridade pela associação com a experiência, de forma que podem falar, estão autorizados a produzir discursos no que se refere às homossexualidades porque são homossexuais e lésbicas, vivenciam essas identidades. Nesse sentido produzem um documentário em que dizem sobre as homossexualidades e num processo performativo de "inventar" uma identidade para a infância. Em nenhum momento são as crianças que aparecem se assumindo como filhos e filhas de lésbicas ou gays, tampouco os adolescentes assumem essa identidade. São os adultos que falam dessas crianças e desses adolescentes como filhos e filhas de lésbicas e gays, são eles quem nomeiam essas crianças e esses adolescentes, inventando uma nova identidade para infância e adolescência. Em um único momento aparece a definição, que é trazida pela voz da comentarista, que está ao fundo: "Algunas personas creen que los hijos y hijas de gays y lesbianas también serán homosexuales, pero ellos no están de acuerdo".

Muitas vezes a identidade parte do outro. No entanto, a identidade sempre precisa de um "outro", que serve para construir uma relação de afastamento e de 
proximidade. Como esse "outro" é essencial para a construção da minha identidade, eu também sou importante para a construção dele como "outro". Dessa forma, é muito comum a homossexualidade partir de um "outro", que assim também está em meio ao seu processo de construção de identidade. Ela pode surgir como agressão, xingamento, desvalorização, como uma forma de esse "outro" se construir no seu oposto, mas também pode se originar pela aceitação, acolhimento, valorização, em que esse "outro" que me acolhe também está se construindo na medida em que outros iguais a ele existem. Daí a necessidade de encontros de famílias homoparentais, como aparece no documentário. Além do reforço desses encontros para a identidade das famílias, das lésbicas e gays como constituídos numa família, ele também tem reflexos para as crianças e adolescentes no sentido de encontrar "outros" iguais a eles e distintos do que comumente se vê.

O documentário passa a ser um "especialista", pois vai construindo um saber sobre essas famílias, suas formas de organização, suas histórias, suas necessidades e suas conquistas. Mas também fala das crianças e vai construindo uma infância como o outro (Larrosa, 2004), na medida em que adjetiva as crianças. Ao estabelecer "filhos e filhas de famílias homoparentais, ou filhos e filhas de lésbicas e gays", estão assumindo a infância como "aquilo que, sempre além de qualquer tentativa de captura, inquieta a segurança de nossos saberes, questiona o poder de nossas práticas e abre um vazio em que se abisma o edifício bem construído de nossas instituições de acolhimento" (idem, p. 96). As crianças filhos e filhas de famílias homoparentais fogem da nossa captura inicial de homogeneizar as infâncias. No entanto, uma vez que a infância é "esse outro que questiona os conhecimentos", ela está sempre sujeita a capturas, mesmo que sejam momentâneas. É o que faz o documentário. Podemos supor que a associação das famílias de lésbicas e gays também considera que seus filhos e filhas sejam algo que foge ao que as escolas estão acostumadas. E, sentindo-se "especialistas" e autorizados a falar disso, produzem um documentário sobre essas famílias e seus filhos e filhas. A elaboração do documentário está implicada na tentativa de capturar essa infância que pode fugir da captura das escolas. $\mathrm{E}$ ao capturar, também organiza os conhecimentos sobre ela, diz o que são, como vivem, do que necessitam, suas angústias, alegrias, enfim, vão "inventando" essas infâncias na medida em que vão capturando, disciplinando e docilizando esses corpos, construindo subjetividades: pais e mães gays e lésbicas, filhos e filhas de pais e mães gays e lésbicas.

Como ressalta Larrosa (2004), a "infância, entendida como um outro, não é o que já sabemos, mas tampouco é o que ainda não sabemos". Por estar no lugar do desconhecido, parece que autoriza e justifica o poder do conhecimento. Como é algo "desconhecido", pode ser capturado e quase "revelado" pelo outro. Durante todo o documentário podemos perceber um sentido de revelação. A câmera entra nas casas, invade a intimidade do cotidiano das famílias, colhe depoimentos de sentimentos vivenciados e isso tudo no sentido de expor e revelar esse desconhecido para o "outro" que assiste. Ao "inventar" os filhos e filhas de famílias homoparentais, o documentário põe essas crianças em continuidade com seus pais. É a identidade 
sexual de seus pais e mães que fornece a identidade social dessas crianças. Mais do que estabelecer uma continuidade entre pais, mães, filhos e filhas pela sexualidade, também serve para criar uma articulação com o mundo, com a atualidade. As imagens não têm sentido em si mesmas, não dizem por si, elas são lidas com base em um contexto. Não é à toa que estamos falando de uma produção do ano de 2009. Existe uma história e um contexto que são condições de emergência do documentário. "Cada época, cultura, grupo social e os sujeitos elaboram seus modos particulares de atribuir sentido aos textos visuais [...]” (Cunha, 2005, p. 172).

Ao falar dessas crianças e ao colocá-las para falar e apresentar as famílias e suas formas de organização, vão "inventando" essas subjetividades por meio dos seus discursos. Dessa forma, essas filhas e esses filhos de lésbicas e gays são uma ficção cultural, dizem de uma cultura.

\section{“NOVOS" DOCENTES}

O que nos permite falar em "novos" docentes, uma vez que os professores não aparecem e sequer são mencionados no documentário? A escola é apenas citada no que se refere à escolaridade das crianças na apresentação das famílias. No entanto, professoras, professores e escola estão presentes o tempo todo. Primeiro, porque é um documentário que é destinado, prioritariamente, para as escolas. Segundo, é um material composto de dois DVDs direcionados à comunidade escolar, o que nos permite pensar na implicação das imagens e dos discursos no processo de formação docente. Sendo o documentário uma versão reduzida dirigida às crianças e aos adolescentes, necessariamente passa pela avaliação das professoras e dos professores, de forma que também exige a presença dos docentes. Por último, ao falar e construir um discurso sobre as famílias homoparentais e sobre os filhos e filhas dessas famílias, filhos e filhas de lésbicas e gays, o documentário investe num "novo" docente, partindo do pressuposto de que esses profissionais não conhecem essa realidade e, portanto, não estão preparados para trabalhar e mesmo lidar com eles. Dessa forma, mais do que simplesmente apresentar e construir isto que chamamos "realidade", as imagens e as falas constroem um discurso. É o aspecto político das produções audiovisuais.

Diante disso, podemos pensar sobre o papel das imagens e dos discursos na educação do olhar dos docentes. Nesse sentido, o documentário e seu direcionamento a escolas, professoras e professores convidam-nos a questionar as práticas culturais que educam o nosso olhar e os efeitos desse olhar sobre quem olha. Como cada vez mais na nossa sociedade há um investimento nas produções audiovisuais com o propósito de educar, de informar e de formar os professores e as professoras, como essas práticas de investimento nas produções de cultura visual (e o documentário é um exemplo disso) estão educando nosso olhar? Há um discurso que é construído, tanto pelas imagens como pelas falas, que vai complementando o que aparece para o espectador. Essas relações em torno da cultura visual e formação docente são mais bem compreendidas quando consideramos seus vínculos e aproximações com as perspectivas pós-estruturalistas, os estudos culturais, os estudos feministas e os estudos gays e lésbicos. 
A cultura visual, como uma trama teórico-metodológica transdisciplinar, preocupa-se não tanto com a leitura de imagens, mas com sua ação como produtoras de subjetividades. Assim, as imagens também podem ser entendidas como discursos, de forma que imagens e falas que aparecem no documentário são portadores e mediadores de significados e de discursos que vão construindo uma realidade, e não "a" realidade. Da mesma forma que, no seu aspecto político, constroem discursos, elas também nos servem para que possamos problematizar e colocar sob suspeita essas ações sobre nós mesmos e sobre os outros. As produções que constituem a cultura visual em que estamos imersos nos possibilitam pensar o mundo que nos cerca e pensar a nós mesmos em nossas posições de sujeito. É o aspecto poético das imagens. $\mathrm{Na}$ construção de um discurso, o documentário trabalha com os cortes, com as ausências e com espaços que nos chamam a lidar com as imagens. Vamos preenchendo esses cortes, ausências e espaços e, quando fazemos isso, não é mais o documentário que está falando, mas somos nós mesmos que, com base nas nossas histórias e experiências, vamos agindo sobre o que nos é mostrado.

Falar do aspecto poético das imagens, desse espaço de resistência e de negociação que está aberto à intervenção daquele que olha, é dar voz ao sentido cultural que todo olhar comporta, como expressão das subjetividades presentes na operação cultural de olhar. Por que conseguimos ver e entender esse documentário, mesmo em língua espanhola e falando de uma suposta realidade catalã? $\mathrm{O}$ que olhamos e a leitura que fazemos estão impregnados pelos vestígios das nossas histórias e culturas. Essas relações que trazemos à tona quando acionamos nossas experiências para leitura das imagens fazem com que cultura visual e formação docente estejam articuladas com o encontro entre passado e presente que nos possibilita dar conta de como vemos e como somos olhados por essas imagens e esses discursos. Para compor essa "realidade" que é apresentada como uma novidade, o roteiro está repleto de recorrências ao passado, não somente com expressões do tipo "esse não é um fenômeno novo", como a utilização de datas: "desde o ano 2005 também é possível a adoção nacional conjunta" ou ainda "desde mais de 30 anos, diversos estudos [...]”. O uso dessas passagens do passado para construir uma noção de avanço, de rompimento com o passado, dá o sentido de estar construindo efetivamente uma nova história e realidade que exigem novos sujeitos, incluindo novas escolas e novos docentes. Esse mecanismo também induz aqueles que estão assistindo a pensar suas realidades e revisar o passado de suas formações na medida em que nos questiona se estamos preparados para isso. Em que momento da minha formação apareceram essas discussões de forma que me possibilita lidar com ela? Assim, o documentário não trabalha ou aciona somente o que as professoras e os professores veem, mas ele acaba situando esses sujeitos, ele dá um lugar para o que chamamos "professoras e professores", na medida em que revela uma "realidade" que está nas escolas e que, cedo ou tarde, inevitavelmente fará parte da sala de aula de cada um.

Nessa relação, o documentário incita-nos a pensar este momento que estamos vivendo e, mais do que isso, ele nos chama a rever nossos olhares sobre as 
sexualidades e suas subjetividades, de forma que podemos agir diretamente nele e em nós mesmos. Assim sendo, acredito que podemos aproximar a cultura visual aos processos de subjetivação. Processos que envolvem saberes, poderes e ação de uns sobre os outros, e de nós sobre nós mesmos (Foucault, 1988, 2009). Principalmente porque essa relação da imagem que nos constitui e do investimento em imagens e em sua utilização nas escolas e nos cursos de licenciaturas como próprio da cultura do século XXI nos coloca o desafio de problematizar nossa vinculação com as tecnologias e com a comunicação, na relação educativa, tanto no que se refere à educação formal quanto à educação dos sujeitos nos seus processos de subjetividade. Com isso, penso que o documentário nos ajuda a implicar a formação docente como atravessada pela cultura, pela cultura visual, pelas sexualidades, de forma que podemos questionar como nos vemos a nós mesmos, professoras e professores, e o mundo. É uma maneira de reafirmar meu entendimento daquilo que estou chamando de "formação docente", sobretudo aquela que é posta em funcionamento com base nas produções audiovisuais. Assim, o documentário permite-me fazer uma interrogação que me parece importante para a formação entendida como resultado de processos de socialização, qual seja: Como as imagens educam o olhar dos docentes e como isso está implicado na constituição dos sujeitos?

Não estou interessado no documentário simplesmente como um objeto cultural, como um conjunto de imagens e falas que constroem discursos. Nem tampouco quero tomá-lo para indagar sobre como podemos utilizá-lo, interpretá-lo. Aproprio-me dele para pensar como se constitui no espaço do vazio (daí se constituir como uma "novidade") e, ao mesmo tempo, como constrói ligações entre esse vazio que traça a distância entre o que vemos (e não conhecemos e/ou que nos assustamos, e/ou que nos motivamos, e/ou que nos apaixonamos) e como somos vistos por aquilo que vemos. Interações que produzem sentido, conceitos, discursos, valores, sujeitos; enfim, constroem dinâmicas e novas práticas sociais.

Ao trazer uma "nova" infância, o documentário acaba agindo sobre os docentes. Não como aquele que já sabe, que já conhece as crianças e a educação e que pode dizer sobre elas. Muito menos como aqueles que serão capazes de integrar essa "nova" infância ao nosso mundo. Sem reduzir e tampouco capturar as infâncias, penso que o documentário age sobre a formação no sentido de deslocar os docentes das "verdades" absolutas e das seguranças, impondo a necessidade de desaprender. O que essas novas constituições de família, de sexualidades e de identidades sociais me fazem repensar? Até que ponto resisto a elas? O que essa resistência diz de mim? Qual é o limite da resistência, silenciosa ou explícita, dessas novas formas de ser e estar no mundo?

Este é o desafio: ultrapassar as resistências na busca por um significado do educativo, que está presente nas imagens, nas "novas" infâncias, nas sexualidades que nos invadem, que nos aprisionam, que nos dão um lugar, que nos apaixonam, de forma que possamos começar a falar sobre o sentido da prática docente desde a própria experiência, algo que se pode descobrir no que fazemos, um sentido mais amplo do que as exigências acadêmicas. Com isso quero dizer que educação é algo 
para além dos conteúdos, maior que a sala de aula e que as escolas, mas que está implicada nos sujeitos que vamos ajudando a construir e como processo no qual nos constituímos juntos, em relação. O investimento dos grupos gays e lésbicos no "novo docente", o investimento da Associação de Famílias Homoparentais na produção desse documentário e sua ação sobre os docentes acaba se traduzindo num tipo de formação que é incorporada não como processo institucionalizado e sistematizado em práticas e técnicas a serem dominadas e exercidas, mas em algo que está ancorado em processos difusos, num tipo de formação que passa pela socialização.

É esse processo que vai do político para o poético que me parece mais produtivo no sentido de possibilitar nas escolas a discussão entre cultura visual e educação, entendendo educação como processo mais amplo de constituição das identidades. O político faz com que possamos reagir a partir daquilo que nos comunica. Passamos a concordar, a questionar, a discordar, a interferir, enfim, somos capturados pelos discursos e imagens e isso passa a fazer parte do nosso processo de subjetivação e pode servir a isso, na medida em que nos colocamos sob suspeita, desconfiamos das nossas certezas.

Os posicionamentos diante de uma produção como o documentário Homo Baby Boom estão diretamente relacionados às histórias de vida e constituição de cada um. Tratando-se de professoras e professores, elas e eles trazem para essas negociações suas formações acadêmicas também, o que significa dizer que trazem para essa negociação entre modos de endereçamento e subjetividades o que foram capazes de ler, discutir e aprender na formação docente. Mais do que isso, podem se apropriar disso para iniciar, nas escolas, um trabalho de discussão em torno dessa presença das imagens no nosso cotidiano. Trabalhar com a relação entre esses aspectos políticos e poéticos das imagens é uma forma de suspeitar das articulações entre imagens, discursos e subjetividades, apostando no processo de mudança social.

Assim, questionar a relação entre cultura visual e processos de subjetividades pressupõe questionar os espaços em que essas relações são construídas como, por exemplo, as escolas e as universidades. Cultura visual e formação docente estão implicadas uma na outra, como práticas questionadoras do social e cultural.

\section{CONSIDERAÇÕES FINAIS}

Uma das leituras que o documentário nos possibilita está ancorada no seu entendimento como lugar de criação de novos comportamentos e novas formas de ser associados à construção das diferenças e identidades. Isso se refere tanto às "novas" formas de ser das famílias, de seus membros, de seus filhos e filhas, como também das escolas e dos docentes. Ao considerar essa afirmação, somos obrigados a pensar as imagens também como discursos, implicadas na construção das identidades.

Os professores e as professoras também participam desse processo coletivo de construção das identidades no interior da escola. O documentário sai da tela 
e passa para a vida, é preenchido pelas experiências. O discurso estabelecido por ele dá lugar aos discursos que constituíram os docentes. Dessa forma, vão trazendo à tona a cultura, os processos discursivos e imagéticos que construíram suas subjetividades ao longo da vida. Em meio a esse processo que passa pela relação com as imagens, somos colocados diante de algumas situações. Por um lado, acreditamos nas imagens e nos satisfazemos com elas na medida em que elas confirmam o que pensamos e acreditamos. Por outro, elas nos incomodam quando não reproduzem a mesma linguagem que queremos ou acreditamos. Esses dois lados estão presentes em qualquer imagem. Diante desse impasse que não é possível de ser resolvido, parece-me que o mais produtivo das imagens é gerar exatamente esse debate, ou seja, quando o aspecto político das imagens é atravessado por seu aspecto poético.

Compreender a cultura visual e a relação de questionamento atribuído à formação de professores está ancorado na perspectiva de que vivemos num mundo repleto de imagens. Estamos em meio a uma extraordinária quantidade de imagens visuais e de imaginários. No entanto, nos aproximarmos dessas imagens representa colocar em circulação uma resposta a elas. Essa resposta depende de uma resposta coletiva e social que vai gerando significado para nós. Algo que é construído por aquilo que vamos considerando como válido, bonito, desejável e que passa pelo aval de grupos qualificados da comunidade. Estamos em uma sociedade que produz cada vez mais imagens que nos ensinam e nos formam.

Dessa forma, não existem fatos e objetos, não existem as famílias homoparentais, os filhos e filhas de lésbicas e gays, senão formas de ver e significar. Afirmação que me parece importante para a formação docente, uma vez que investe muito mais na análise das culturas do que dos sujeitos. Ver, sentir e desejar são resultados de construção cultural num exercício complexo que envolve emoções, memórias, discursos, tradição, grupos sociais, família; é o ponto de partida básico para se pensar a escola, o professor e as relações que são estabelecidas entre ensinar e aprender. Além disso, coloca no centro das discussões a formação e o currículo no seu envolvimento político de pensar a produção do que chamamos realidade. Cultura visual e formação de professores, portanto, diz do impacto político das imagens e dos estudos visuais na produção de imaginários, de coletivos e de reconhecimento identitário. E por consequência nos coloca diante da necessidade de pensar essas questões como produções históricas e concretas, que constroem determinadas subjetividades e sociabilidades, mas que podem ser desconstruídas e reconstruídas.

\section{REFERÊNCIAS}

ButLer, Judith. Lenguaje, poder y identidad. Madrid: Editorial Síntesis, 2009.

Cunha, Susana R. V. da. Educação e cultura visual: uma trama entre imagens e infância. 2005. Tese (Doutorado em Educação) - Universidade Federal do Rio Grande do Sul. 
Ellsworth, Elizabeth. Modos de endereçamento: uma coisa de cinema, uma coisa de educação também. In: Silva, Tomaz Tadeu da. Nunca fomos humanos: nos rastros do sujeito. Belo Horizonte: Autêntica, 2001.

Foucault, Michel. Vigiar e punir: nascimento da prisão. Petrópolis: Vozes, 1987.

. História da sexualidade I: a vontade de saber. Tradução de Maria Thereza da Costa Albuquerque e José Augusto Guilhon Albuquerque. Rio de Janeiro: Graal, 1988. 2009. . El yo minimalista y otras conversaciones. Buenos Aires: La Marca Editora,

LARROSA, Jorge. O enigma da infância: ou o que vai do impossível ao verdadeiro. In: . Pedagogia profana: danças, piruetas e máscaras. 4. ed. Belo Horizonte: Autêntica, 2004.

Uziel, Ana Paula. Homossexualidade e adoção. Rio de Janeiro: Garamond, 2007.

WOODWARD, Kathryn. Identidade e diferença: uma introdução teórica e conceitual. In: Silva, Tomaz T. da (Org.). Identidade e diferença: a perspectiva dos estudos culturais. 4. ed. Petrópolis: Vozes, 2000.

\section{SOBRE O AUTOR}

Anderson FerRari é doutor em educação pela Universidade Federal de Juiz de Fora (UFJF). Professor do Colégio de Aplicação João XXIII e da UFJF. E-mail: aferrari13@globo.com 


\section{ANDERSON FERRARI}

\section{Cultura visual e homossexualidades na constituição de "novas" infâncias e "novos" docentes}

Este artigo visa estabelecer pontos de encontro entre a formação docente, educação infantil e relações de gênero e sexualidades. Para isso, aproprio-me de um documentário produzido por uma associação de famílias homoparentais, voltado para escola e, em especial, de uma versão reduzida dessa produção audiovisual direcionada a crianças e adolescentes, para problematizar o campo da cultura visual na constituição de subjetividades. Herdeira do pós-estruturalismo, dos estudos culturais, feministas e dos gays e lésbicos, a cultura visual diz de algo para além da leitura de imagens, pensando na sua ação como produtoras de subjetividades. Assim sendo, discursos, imagens e falas que aparecem no documentário são portadores e mediadores de significados, de forma que vão construindo uma realidade, e não "a" realidade; produzindo sexualidades, "novas" infâncias e "novos" docentes.

Palavras-chave: cultura visual; sexualidades; subjetividades.

\section{Visual culture and homosexualities in the formation of "new" childhoods and "new" teachers}

This paper aims at establishing the meeting points between teacher's formation, children's education and their relations to gender and sexualities. For such, I take for granted a documentary produced by an association of homoparental families to the schools and mainly a reduced version of this audiovisual production directed towards children and teens. My objective is to analyze the role of visual culture in building the subjectivity. As an heir of pos-structuralism, and of the cultural, feminist, gays and lesbian studies, the visual culture is expressed far beyond the reading of images and it gets to be quite relevant to produce the subjectivity. Therefore, the speechs, images and discourses from the 
documentary carry on and negotiate several meanings on the construction of a reality, different from "the" reality, "new" childhoods and "new" teachers.

Keywords: visual culture; sexualities; subjectivities.

\section{Cultura visual y homosexualidades en la formación de "nuevas" infancias y "nuevos" maestros}

Este artículo tiene como objetivo establecer puntos de contacto entre la formación del profesorado, educación infantil y las relaciones de género y la sexualidad. Para ello, me apropio de un documental producido por una asociación de familias homoparentales destinado a las escuelas y, en particular, de una versión reducida de producción audiovisual dirigida a niños y jóvenes, para problematizar el campo de la cultura visual en la constitución de las subjetividades. Heredero del post-estructuralismo, de los estudios culturales, feministas y de gays y lesbianas, la cultura visual dice algo más allá de la lectura de la imagen, interesada en su acción como productora de subjetividad. Por lo tanto, los discursos, imágenes y palabras que aparecen en el documental son los portadores y mediadores de significados, de modo que van construyendo una realidad y no "la" realidad, poniendo en acción la producción de las sexualidades, "nuevas" infancias y "nuevos" maestros.

Palabras clave: cultura visual; sexualidad; subjetividades. 